\begin{tabular}{|l|l|l|}
\hline \multicolumn{2}{|c|}{ PublisherInfo } \\
\hline \hline PublisherName & $:$ & BioMed Central \\
\hline \hline PublisherLocation & $:$ & London \\
\hline \hline PublisherImprintName & $:$ & BioMed Central \\
\hline \hline
\end{tabular}

\title{
BRCA1-associated DNA repair
}

\begin{tabular}{||l|l|l||}
\hline \multicolumn{2}{|c||}{ ArticleInfo } \\
\hline \hline ArticleID & $:$ & 3620 \\
\hline \hline ArticleDOI & $:$ & $10.1186 /$ bcr-1999-66598 \\
\hline \hline ArticleCitationID & $:$ & 66598 \\
\hline \hline ArticleSequenceNumber & $:$ & 40 \\
\hline \hline ArticleCategory & $:$ & Paper Report \\
\hline ArticleFirstPage & $:$ & 1 \\
\hline \hline ArticleLastPage & $:$ & 4 \\
\hline \hline & $:$ & RegistrationDate : 1999-8-3 \\
ArticleHistory & $:$ & OnlineDate $:$ 1999-8-3 \\
\hline \hline ArticleCopyright & $:$ & Current Science Ltd1999 \\
\hline \hline ArticleGrants & $:$ & \\
\hline \hline ArticleContext & $:$ & 1305811 \\
\hline \hline
\end{tabular}




\section{Keywords}

breast, BRCA1, DNA damage, Rad50, repair

\section{Introduction}

The BRCA1 gene is mutated in approximately half of all hereditary breast cancers. Although the precise function of its gene product is unknown, several lines of evidence have suggested a role for the BRCA1 protein in response to DNA damage. The entire BRCA1 sequence shows no homology with that of any known protein; however, several functional motifs have been defined, including a RING finger domain, a carboxy-terminal domain known as BRCT, and binding sites for tumor suppressor p53 and DNA repair protein hRad51. An increasing number of known or new regulatory proteins have been associated with BRCA1.

\section{Aims}

To identify and characterize potential binding partners for BRCA1 that might elucidate its role in DNA repair.

\section{Comments}

Previous reports had suggested an association between BRCA1 and hRad51-mediated cellular responses to DNA damage. Discussion has also arisen as to the involvement of hRad50, but evidence linking the two pathways has previously been absent. Here for the first time the authors illustrate the involvement of BRCA1 with the hRad50 hMre11 p95 complex, which may act as a sensor of DNA damage. The link between BRCA1/BRCA2 and the hRad50/hRad51-mediated response to DNA damage leads to the possibility that hereditary breast cancers may have differential sensitivity to specific chemotherapeutic agents and irradiation, which may in turn have implications for clinical outcome.

\section{Methods}


T24 bladder carcinoma cells were immunoprecipitated with BRCA1 antibodies to reveal three coprecipitated cellular proteins. The largest, a $150 \mathrm{kDa}$ protein, was found to be $\mathrm{hRad} 50$ by reprecipitation with a specific monoclonal antibody. The specific binding sites of hRad50 and BRCA1 were determined using GST pull-down and yeast two-hybrid assays. Investigations of BRCA1 and hRad50 interactions after DNA damage were carried out by treating T24 cells with gamma irradiation or methyl methanesulfonate (MMS), and co-immunoprecipitating cell lysates with specific anti-BRCA1 and antihRad50 monoclonal antibodies. Irradiation-induced foci were also assayed for hRad51, hMre11 and p95 in T24 and HCC1937 cells. Cell survival after MMS treatment was measured in HCC1937, T24 and MCF7 cells. Transfection of cells with wild-type and mutant BRCA1 was also carried out. Expression of these constructs was confirmed by protein immunoblot analysis.

\section{Results}

The specific binding site for hRad50 on the BRCA1 protein was found to be a fragment containing amino acids 341 to 748 . The amino-terminal half of hRad50 was required for BRCA1 binding. Treatment of T24 cells with gamma irradiation or MMS did not appear to alter the amount of BRCA1 hRad50 complex, suggesting that it exists even in the presence of DNA damage. Both BRCA1 and hRad50 display discrete nuclear foci after treatment of cells with genotoxic agents. Among cells displaying both hRad50 and BRCA1 foci after gamma irradiation, $>90 \%$ showed substantial colocalization. Co-localization of BRCA1 and hRad51 has also been reported, and these two types of foci appear to be mutually exclusive. Radiation-induced hMre11 and p95 foci were also shown to co-localize with BRCA1 and hRad50 (with which they form a complex). BRCA1, hRad50, hMre11 and p95 irradiation-induced foci were all found to be diminished in HCC1937 breast cancer cells, which express a carboxy-terminally truncated BRCA1 protein. Transfection of wild-type BRCA1 into the HCC1937 cells restored these foci, implicating BRCA1 in the defective response of these proteins in HCC1937 cells. The truncated BRCA1 protein, present in detectable levels in these cells, was found to be absent from the hRad5 hMre11 p95 complex. HCC1937 cells were found to be hypersensitive to MMS compared with T24 and MCF-7 cells, both of which express the full-length BRCA1 protein. Transfection of wild-type, but not mutant, BRCA1 substantially increased survival of MMS-treated HCC1937 cells. In contrast, transfection with wild-type BRCA2 did not affect cell survival under the same conditions.

\section{Discussion}

A strong association is shown for the BRCA1 protein and the hRad50-mediated response to DNA damage. The hRad50 hMre11 p95 complex participates in nonhomologous end joining or homologous recombination in double-strand breaks. Efficient DNA double-strand break repair is important because unrepaired lesions can lead to chromosome break, translocation, and other forms of genetic instability seen in human cancer cells. In homologous recombination, it is thought that the hRad50 hMre11 p95 complex is responsible for end processing, and hRad51 is involved in strand exchange during a subsequent phase. The data presented here suggest that formation of the BRCA1 hRad50 complex does 
not alter in response to DNA damage; rather, it is the nuclear partitioning of the complex that changes. BRCA1 is present in both $\mathrm{hRad} 50$ and $\mathrm{hRad} 51$ foci upon irradiation, although the two are mutually exclusive. It is possible that BRCA1 may facilitate the coupling of the hRad50- and hRad51-mediated responses to DNA damage. This hypothesis is supported by evidence that BRCA2 is associated with hRad51 and that BRCA1 interacts with BRCA2.

\section{References}

1. Zhong Q, Chen C-F, Li S, Chen Y, Wang, CC Xiao, J Chen PL, Sharp ZD, Lee WH: Association of BRCA1 with the hRad50 hMre11 95 complex and the DNA damage response. Science. 1999, 285 :

747-750. 